\title{
Articulação entre o Conselho Consultivo da Anvisa e o Conselho Nacional de Saúde: uma análise no período de 2000 a 2010
}

| ${ }^{1}$ Regina Célia Borges de Lucena |

Resumo: O estudo analisou os debates, no período de 2000 a 2010, no Conselho Nacional de Saúde (CNS) e na Comissão Intersetorial de Vigilância Sanitária e Farmacoepidemiologia (CIVSF), sobre os temas da vigilância sanitária e articulação com o Conselho Consultivo da Agência Nacional de Vigilância Sanitária (Anvisa). A pesquisa documental, de natureza qualitativa, que analisou 163 atas de reuniōes do CNS e da CIVSF, e demais documentos a elas relacionados, buscou reunir informaçôes sobre o contexto político-institucional e as interfaces e conexôes entre as três instâncias. Observouse baixa inserção do tema "vigilância sanitária" na pauta do CNS e uma atuação insuficiente da CIVSF para o fortalecimento desse debate. Conclui-se pela fragilidade de integração entre o Conselho Consultivo da Anvisa e as instâncias de controle social no Sistema Único de Saúde. Esse resultado é fruto de dificuldades de comunicação interinstitucional e da baixa inserção da vigilância sanitária no SUS, historicamente construída.

> Palavras-chave: vigilância sanitária; política de saúde;

Recebido em: 26/06/2014 participação comunitária.

1 Universidade Federal do Recôncavo da Bahia. Santo Antônio de Jesus-BA, Brasil. Endereço eletrônico: regina. lucena@ufrb.edu.br 


\section{Introdução}

O setor saúde tem importância fundamental no debate e implementação do controle social de políticas públicas. Desde o final da década de 1970, a participação popular ${ }^{1}$ no processo de produção e execução da política de saúde já era considerada um requisito pelo movimento de Reforma Sanitária. Sua garantia constitucional na gestão da saúde foi regulamentada pela Lei no 8.142, de 28 de dezembro de 1990, que dispõe sobre a participação da comunidade na gestão do Sistema Único de Saúde (SUS). Essa normativa estabelece, em seu Artigo 1º que o exercício da participação em saúde se dê por meio de duas instâncias colegiadas, a Conferência e o Conselho de Saúde (BRASIL, 1990).

Os conselhos de saúde, órgãos de caráter permanente e deliberativo, diferem da estrutura tradicional de conselhos, normalmente conformados por estratos burocráticos ou dominados por grupos, lobbies e setores específicos (ESCOREL; $\mathrm{BLOCH}, 2005)$. A regra para a representação dos usuários, que deve ser paritária em relação ao conjunto dos demais segmentos, indica sua estreita vinculação aos movimentos sociais. Esse modelo implica reconhecer interesses diferentes e contraditórios na sociedade, bem como visa à formulação dialógica de políticas e ao acompanhamento de sua execução por parte da população. Isso representa, no setor saúde, segundo a síntese de Vanderlei e Witt (2003, p. 133), “as condições para o exercício da cidadania por meio da participação da população nos órgãos colegiados." Dessa forma, esses conselhos exercem um papel primordial no exercício do controle social em saúde, a despeito de diversas fragilidades já identificadas na sua atuação (BRASIL, 2007; LABRA, 2005).

A instância máxima de deliberação do SUS é o Conselho Nacional de Saúde (CNS), instituído em 1937 e atualmente vinculado ao Ministério da Saúde. É composto por um total de 144 representantes, sendo 48 conselheiros titulares, cada um com dois suplentes. A Comissão Intersetorial de Vigilância Sanitária e Farmacoepidemiologia (CIVSF) foi instituída, juntamente com as outras seis Comissões definidas no texto legal, por meio da Resolução CNS no 11, de 1991. De acordo com essa normativa, as comissões intersetoriais, entre outras competências, propõem as medidas que julgarem cabíveis para o aperfeiçoamento das políticas, programas e ações de que tratam as respectivas áreas temáticas. São compostas por representantes de órgãos governamentais de âmbito nacional (e seus centros de referência) e de entidades civis relacionadas às suas temáticas, quer 
sejam de prestadores de serviços, de profissionais, de usuários ou de proteção e

defesa do cidadão. Os representantes são indicados pelos dirigentes das diferentes organizaçôes e designados pelo Ministro de Estado da Saúde.

A Agência Nacional de Vigilância Sanitária (Anvisa) foi criada em 1999, por meio da Lei no 9.782, integra o SUS e é entidade vinculada ao Ministério da Saúde. De um modo geral, as agências são marcadas, em sua arquitetura institucional, pela noção de independência administrativa e especialização técnica. Isso evitaria, em tese, sua vulnerabilidade a pressões externas, seja do esquema político-eleitoral da administração direta, seja dos diversos grupos de interesse existentes na sociedade. Por outro lado, essa arquitetura institucional pode levar ao insulamento burocrático e baixa permeabilidade à participação democrática da sociedade (DINIZ, 2001). Num contexto da cultura política brasileira, autoritária e patrimonialista, essas características permitem a ação direta ou indireta de grupos corporativos com forte capacidade de interferência no jogo regulatório (BAIRD, 2012).

A despeito desses obstáculos, os espaços participativos da Anvisa têm avançado nos últimos anos no que diz respeito à transparência. Entretanto, em alguma medida reproduzem características e falhas que limitam a efetividade de sua contribuição para a participação democrática em saúde (ALVES, 2008; DASSO JR, 2006). Este artigo tem o objetivo de analisar os debates, no período de 2000 a 2010, no CNS e na CIVSF, sobre os temas da vigilância sanitária e articulação com o Conselho Consultivo da Anvisa. ${ }^{2}$

\section{Metodologia}

$\mathrm{O}$ estudo, de natureza qualitativa, foi desenvolvido por meio de pesquisa documental, que teve como base a análise das atas de reunióes do CNS e da CIVSF, e demais documentos a elas relacionados, tais como resoluções e moções. Foram analisadas 163 atas no total, referentes ao período de 2000 a 2010, com o objetivo de identificar o contexto político-institucional e as interfaces e conexões entre as três instâncias. Esse período contempla a última gestão do Presidente Fernando Henrique Cardoso (1998-2002) e as duas gestōes do Presidente Lula (2003-2006 e 2007-2010). Seis ministros ocuparam a pasta da Saúde, sendo também presidentes do Conselho Nacional de Saúde. Foram utilizadas as atas do CNS disponíveis na página do Conselho; por não estarem disponíveis publicamente, as atas da CIVSF foram solicitadas diretamente à Comissão, por meio do Serviço de Informação ao Cidadão do Ministério da Saúde. 
Os dados foram descritos e analisados por meio de análise de conteúdo, utilizando-se as etapas propostas por Bardin (1977): pré-análise, exploração do material e tratamento dos resultados. Após uma leitura flutuante, os documentos foram organizados, classificados e analisados segundo período estudado, com identificação dos temas mais frequentes e debates relacionados. A utilização dessa estratégia resultou no delineamento de três fases, a partir das quais os documentos são analisados: 2000-2002; 2003-2005; e 2006-2010. Essas fases refletem, essencialmente, três períodos de gestão dos diretores-presidentes da Anvisa, porém também dizem respeito a contextos políticos e institucionais que trazem singularidades à atuação desses espaços participativos.

\section{Resultados}

\section{O Conselho Consultivo da Anvisa}

O Conselho Consultivo integra a estrutura organizacional básica da Anvisa, estabelecida na Lei no 9.782/1999, que criou a Agência. Sua composição e competências serão detalhadas posteriormente, no Regulamento da Agência, por meio do Decreto no 3.029/1999 e no seu Regimento Interno, por meio da Portaria no 354/2006. De acordo com o Regulamento da Agência, as competências do Conselho incluem a proposição de diretrizes e recomendações técnicas sobre os assuntos de competência da Anvisa.

Com relação ao seu funcionamento, o Conselho Consultivo deve se reunir ordinariamente a cada três meses e é presidido pelo Ministro de Estado da Saúde ou por seu representante legal. O diretor-presidente da Anvisa deve participar das reuniões, porém sem direito a voto. O Conselho possui 13 membros previstos, com maior proporção do governo, com cinco representantes - três da União, um de unidades federadas e um de municípios; o setor regulado possui três representantes; defesa do consumidor e comunidade científica, dois representantes cada; e um membro do Conselho Nacional de Saúde.

O Conselho Consultivo da Anvisa tem, por sua própria natureza, funções voltadas para a construção de consensos entre atores sociais que expressam demandas e interesses relacionados à vigilância sanitária. De alguma forma, entretanto, suas competências expressam funções propositivas, como é o caso de "opinar sobre as propostas de políticas governamentais na área de atuação da Agência, antes do encaminhamento ao Ministério da Saúde”. Nesse caso, supõe- 
se, ainda, que o Conselho possa funcionar como um dos elos de articulação entre a Agência e seu ministério supervisor.

Embora sem caráter deliberativo, as quatro competências legais do Conselho Consultivo dizem respeito a funções opinativas, propositivas e de controle/ acompanhamento. Segundo seu Regimento Interno, as deliberaçôes aprovadas devem ser emitidas na forma de recomendações, de caráter público. Os pareceres e recomendações do Conselho Consultivo poderão ser enviados ao Ministério da Saúde ou Conselho Nacional de Saúde, quando julgar necessário ou pertinente.

$\mathrm{O}$ fato de se constituir uma instância consultiva implica maior fragilidade desse tipo de conselho, já que a incorporação das opiniōes e posicionamentos por ele emitidos depende, basicamente, da vontade dos dirigentes da instituição ou governantes da política. Ainda assim, um conselho consultivo pode ser um espaço em potencial para o debate público sobre questôes relevantes da política a que está vinculado. No caso da vigilância sanitária - um campo, por sua forma de atuação, pouco afeto ao controle social -, a importância desse espaço também está ligada à possibilidade de democratização do debate dentro de uma agência reguladora, quebrando o tradicional insulamento dessas instituições.

\section{O debate sobre vigilância sanitária no Conselho Nacional de Saúde}

Entre fevereiro de 2000 e dezembro de 2010, a vigilância sanitária constou como pauta de discussão no CNS em 13 reuniões. O quadro 1 descreve os temas de vigilância sanitária que constituíram itens de pauta no Conselho Nacional de Saúde.

Quadro 1. Temas pautados no Conselho Nacional de Saúde sobre Vigilância Sanitária, 2000 a 2010.

\begin{tabular}{|l|l|c|}
\hline \multirow{2}{*}{\multicolumn{1}{c|}{ TEMÁTICA }} & \multicolumn{2}{c|}{ ITEM DE PAUTA } \\
\cline { 2 - 3 } & $\mathrm{N}$ & $\%$ \\
\hline Bens e serviços sob regulação sanitária & 08 & 57,1 \\
\hline Descentralização em vigilância sanitária & 03 & 21,5 \\
\hline Inserção da vigilância sanitária no SUS & 02 & 14,3 \\
\hline Controle social em vigilância sanitária & 01 & 7,1 \\
\hline TOTAL & 14 & 100 \\
\hline
\end{tabular}

Fonte: própria autora 
$\mathrm{Na}$ primeira fase analisada, de 2000 a 2002, as discussōes sobre vigilância sanitária no Conselho Nacional de Saúde se referiram preponderantemente aos debates sobre assistência farmacêutica e organização da I Conferência Nacional de Vigilância Sanitária. Nesse período, a questão dos medicamentos tinha alta visibilidade no país, inclusive com a instalação de Comissão Parlamentar de Inquérito sobre o tema. A comissão dos medicamentos foi instalada em novembro de 1999, em razão de indícios de aumento abusivo nos preços de medicamentos, além das denúncias de falsificação. $\mathrm{O}$ encerramento dos trabalhos da CPI e publicação final do relatório aconteceu em maio de 2000, demonstrando a existência de preços abusivos, lucros exorbitantes, prática de cartel, propaganda enganosa, além da fragilidade da indústria farmacêutica e dos órgãos de controle.

No CNS, a ênfase do debate sobre a Anvisa foi quanto ao seu papel na regulação dos preços de medicamentos:

[O Diretor-Presidente da Anvisa] "Informou que a ANVISA estava participando da construção da Política Nacional de Medicamentos por meio da regulamentação e do controle de preços dos medicamentos e que, nesse sentido, seria necessário instituir a avaliação fármaco-econômica até mesmo na aprovação de novos fármacos, sendo necessário o apoio da sociedade." (CNS, ata da 116ª reunião, realizada em 6 e 7 de fevereiro de 2002).

O debate esteve inserido numa discussão mais ampla sobre assistência farmacêutica, que incluiu o uso racional de medicamentos e a necessidade de fortalecimento dos laboratórios oficiais e públicos. Além disso, desde esse período havia questionamentos sobre o controle social a ser exercido sobre a Anvisa. Esse tipo de questionamento apareceu também nos dois itens em que a vigilância sanitária foi objeto de pauta no período. No primeiro, sobre a organização da I Conferência Nacional de Vigilância Sanitária, foram identificados problemas na representação dos usuários e na conceituação dos gestores. No segundo item, sobre a descentralização em vigilância sanitária, foi questionada a interface com o controle social que, segundo a resposta do então diretor-presidente da Anvisa, estava condicionada às ações de comunicação social da Agência:

[O Diretor-Presidente da Anvisa] Informou, ainda, que a vigilância sanitária possuía diversas ações na área da comunicação social, acrescentando que as campanhas sanitárias deveriam se inseridas nos veículos de comunicação com valor diferenciado, tendo em vista o seu valor social de construção da cidadania (CNS, ata da $113^{a}$ reunião, realizada em 3 e 4 de outubro de 2001). 
A única menção ao Conselho Consultivo aconteceu quando do

questionamento, por parte de um conselheiro, ao então ministro da Saúde, sobre o controle social na Agência:

Conselheiro G (Entidade Nacional de Portadores de Patologia e Deficiência)

"Minha questão é a respeito de um controle social mais próximo da Agência Nacional de Vigilância Sanitária e, também, em relação aos planos de saúde. Apesar de o Conselho ser o maior órgão de controle social na saúde, temos uma experiência importante, que é a Câmara de Saúde Suplementar, que infelizmente não têm se reunido, em função da criação da Agência." O Senhor Ministro [da Saúde] - "A Agência já possui um Conselho, que agora não me lembro qual é. A agência é apenas uma integrante na questão dos medicamentos. Acho importante que os trabalhos sejam retomados (CNS, ata da $94^{\text {a }}$ reunião, realizada em 9 e 10 de fevereiro de 2000).

A segunda fase, de 2003 a 2005, foi marcada, no Ministério da Saúde, pela mudança de governo e, consequentemente, no comando da pasta. $\mathrm{O}$ novo ministro e sua equipe receberam o apoio do Conselho Nacional de Saúde, expressa na Deliberação n. ${ }^{\circ}$ 002/2003, com manifestação de reconhecimento e aprovação da atuação. Ainda no início de 2003, foi apresentada uma nova estrutura de funcionamento do Ministério com extinção de três secretarias e criação de quatro novas (BRASIL, 2003). ${ }^{3}$

Entretanto, apesar da expectativa favorável e da assunção do discurso de fortalecimento do SUS pelo governo, a avaliação dessa primeira fase aponta para a polarização entre os dois projetos em disputa no setor saúde - o de reforma sanitária e o privatista (BRAVO; MENEZES, 2011). A continuidade da política econômica de caráter neoliberal contrastou com as iniciativas que pareciam buscar mudanças no modelo de atenção à saúde. Apesar dos avanços desse período, inclusive quanto ao controle social, com a realização da $12^{\text {a }}$ Conferência Nacional de Saúde e a criação da Secretaria de Gestão Participativa no Ministério da Saúde, ficaram evidentes fortes expressões de continuísmo da política de saúde da década de 1990. Bravo e Menezes (2011, p. 18) apontam, entre esses aspectos, "a ênfase na focalização, na precarização, na terceirização dos recursos humanos, no desfinanciamento e a falta de vontade política para viabilizar a concepção de Seguridade Social”.

Quanto ao Conselho Nacional de Saúde, essa fase se iniciou com a decisão, na $130^{a}$ reunião, realizada em maio de 2003, de não mais participar de instâncias consultivas nas duas agências da área de saúde. A decisão se baseou na ideia 
de não legitimar espaços de participação precários e frágeis, na dificuldade de indicação de um apenas um membro que representasse toda a diversidade do CNS e no risco de enfraquecer e diluir seu poder deliberativo. A partir daí, a vigilância sanitária apareceu de forma pontual em diversas reuniões, vinculada a temas mais amplos, como o Programa Fome Zero (então em implementação), assistência farmacêutica no SUS e, ainda, nos debates sobre política regulatória do setor saúde. Nos dois itens que foram pontos de pauta nesse período, a política de vigilância sanitária e o fracionamento de medicamentos, as discussões se concentraram sobre o papel da Anvisa no controle dos preços dos medicamentos.

Com a reestruturação da CIVSF (BRASIL, 2008), ficou decidido que o eixo temático de assistência farmacêutica estaria inserido naquela comissão. A partir daí, vários assuntos sobre vigilância sanitária são remetidos à CIVSF e, também, relatados ao CNS por meio dos informes da comissão. O debate sobre o controle social na Agência permanece durante todo o período e constitui um dos principais questionamentos quando da apresentação de um dos dois itens que foram pontos de pauta nesse período, a política de vigilância sanitária. Vários conselheiros enfatizaram a necessidade de maior aproximação e interlocução entre a Anvisa e o Conselho Nacional de Saúde. Foram feitas duas mençōes ao Conselho Consultivo da Anvisa nesse período. A primeira, na $145^{\mathrm{a}}$ reunião, tratou de convite para a participação do CNS na 17a reunião do Conselho Consultivo, o que não aconteceu. Depois, na 160a , o Conselho Consultivo solicitou pauta na reunião da CIVSF.

A terceira fase, de 2006 a 2010, ocorreu praticamente sem mudanças quanto às prioridades anteriores, mas trazia o financiamento na saúde como o grande desafio a ser enfrentado. Como parte do ideário desse contexto, estava a noção de gestão eficiente do SUS, materializada no Pacto pela Saúde, lançado em 2006. Este substituiu a habilitação dos municípios pela formalização de termos de compromisso de gestão, com atribuições e metas a cumprir. A perspectiva era, segundo Guerreiro e Branco (2001, p. 1696), a "possibilidade de materialização de acordos voltados à repartição dos recursos e responsabilidades, mas principalmente para o estabelecimento da responsabilização solidária entre os gestores.” Além da continuidade da política e programas vigentes no Ministério da Saúde, o período destacou-se pelo enfrentamento de questōes até então não resolvidas, como a quebra de patente de um medicamento contra a síndrome da imunodeficiência adquirida (Aids) e a defesa do debate sobre a legalização do aborto. 
Nesse contexto, a terceira fase foi inaugurada, no Conselho Nacional de Saúde, com a fala do então secretário-executivo que, na condição de servidor da Anvisa, pontuou questôes de vigilância sanitária quando da apresentação do Pacto pela Saúde e em outros assuntos tratados.

Eu tinha a premência de tentar trazer a discussão sobre a vigilância sanitária para dentro do ambiente do Sistema Único de Saúde. Eu tive a oportunidade de conversar com alguns conselheiros que estão aqui, alguns foram convidados quando nós realizamos a 1a Conferência Nacional de Vigilância Sanitária e era muito difícil tentar trazer para discussão um tema que não era prioridade dos gestores, dos técnicos, dos Conselhos. Nós temos que ter a autocrítica de dizer isso, não era uma prioridade. Nós estivemos aqui no Conselho algumas vezes e fizemos grandes discussōes que nos ajudaram a implantar o plano de trabalho da ANVISA e nós temos que sempre consolidar essa discussão (CNS, ata da 162a reunião, realizada em 7, 8 e 9 de fevereiro de 2006).

Esse período ficou configurado, no Conselho Nacional de Saúde, como o momento de maior aproximação da Anvisa, expressa no número de itens pautados, o maior do período estudado, e nos sucessivos debates sobre o tema. É também desse período a maioria das recomendações e todas as moções relativas à Anvisa, publicadas entre 2000 e 2010. Embora os debates não fossem isentos de críticas quanto à sua atuação, dificuldades no campo do controle social e ausência de uma política (formal) de vigilância sanitária, oito das nove moções emitidas foram de apoio a iniciativas e à gestão da Agência.

Dois tipos de abordagem do Conselho Nacional de Saúde aparecem nessa fase. $\mathrm{O}$ primeiro diz respeito às citações sobre a Anvisa, seja nos informes da CIVSF, seja nas discussões de temas relacionados. São recorrentes as críticas quanto à falta de uma política formal de vigilância sanitária, que seria um obstáculo para a adequada atuação da Agência, e também intervenções a respeito da necessidade de maior aproximação com o CNS.

[...] falta debate no controle social sobre as questôes de vigilância sanitária e de farmacovigilância; há no site da ANVISA o sistema nacional de vigilância sanitária composto pelo Ministério da Saúde, CONASS,CONASEMS, secretarias estaduais e municipais de saúde, e os conselhos estaduais e municipais, não fazendo parte dessa composição o CNS; o debate sobre vigilância sanitária precisa vir para o CNS, porque é muito rico e significativo; a vigilância sanitária é um instrumento de intervenção do estado no processo de proteção e promoção da saúde da população; [...] há necessidade de ser debatida e formulada uma política nacional de vigilância sanitária; [...] o CNS precisa exercer o controle social sobre as açôes da ANVISA, dada a importância que representa para a qualidade de vida da população" (CNS, ata da $185^{\mathrm{a}}$ reunião, realizada em 14 e 15 de maio de 2008). 

prejuízos da falta de uma política nacional de vigilância sanitária com repercussão na dificuldade de integração das ações na saúde (CNS, ata da 200ª reunião, realizada em 12 e 13 de agosto de 2009).

A segunda abordagem é referente aos pontos de pauta apresentados pela Anvisa nesse período. A maioria tratou de assuntos técnicos, principalmente relativos à regulamentação exercida pela Agência, resultando em debates também de caráter técnico e várias moções de apoio. Embora os debates apontassem questôes políticas, como cidadania e interesse público, ou de saúde coletiva, como quadro de saúde e impacto para a população, a tônica principal foi direcionada para as questôes técnicas de cada tema. Nessas discussões, a maior parte das manifestações constituíam questionamentos focais ou intervenções de caráter positivo sobre a atuação da Anvisa.

Conselheira F (Conselho federal de Nutrição) também cumprimentou os integrantes da mesa pela apresentação e registrou o papel relevante da ANVISA e sua iniciativa de aproximação do controle social. Também perguntou sobre a regulamentação dos transgênicos e da propaganda de alimentos infantis. Por fim, propôs que o Plenário aprovasse moção de apoio à ANVISA pelos serviços relevantes à saúde pública brasileira (CNS, ata da 177a reunião, realizada em 12 e 13 de setembro de 2007).

Essa conotação positiva do Conselho quanto à atuação da Anvisa fica clara em oito moções de apoio publicadas entre 2007 e 2010. A aparente contradição entre o esvaziamento do debate no Conselho Consultivo nesse período (LUCENA, 2013) e as sucessivas manifestações de apoio à Agência por parte do Conselho Nacional de Saúde revelam, em primeiro lugar, o distanciamento entre esses dois espaços participativos. A baixa articulação e diálogo entre os dois conselhos resultam no descompasso entre as dinâmicas implementadas no período, bem como a ausência do compartilhamento de pautas e recomendações. A abordagem do Conselho Nacional de Saúde se restringiu às pautas oferecidas pela Anvisa, já que o debate em torno de temas relacionados à vigilância sanitária foi remetido a um terceiro espaço, a Comissão Intersetorial de Vigilância Sanitária e Farmacoepidemiologia. Além disso, há pouco debate sobre a política de vigilância sanitária, o que reforça a ideia de que o Conselho Nacional de Saúde tem sido um espaço, por excelência, que atribui legitimidade à atuação da vigilância sanitária, sem a devida discussão sobre o seu papel de coordenação do Sistema Nacional de Vigilância Sanitária (MAIA, 2012).

Por outro lado, a Agência empreendeu esforços no sentido de fortalecer a relação com o CNS, com a apresentação sistemática de suas ações e iniciativas, 
o que foi capaz de construir certo grau de consenso quanto à legitimidade de sua atuação. Dagnino (2002) aponta diversas estratégias utilizadas pelo Estado para dificultar a partilha de poder decisório. Por um lado, podem ser usadas, por parte do governo, as abordagens de neutralização e enfraquecimento do papel do conselho. Por outro, as entidades da sociedade civil exploram a existência de projetos heterogêneos dentro do próprio Estado, estabelecendo parcerias e consensos. $\mathrm{O}$ estabelecimento de uma relação de comunicação e diálogo, por parte da Agência, certamente tornou a correlação de forças favorável à visibilidade positiva, no CNS, dos atos regulatórios praticados no período. Foi também durante esse período que as agências reguladoras passaram por um intenso processo de partidarização, com indicação dos dirigentes pelos partidos que formavam a base de sustentação do governo ou por integrantes da cúpula governista. Além do consenso estabelecido pela via técnica, a coalizão dos partidos aliados do governo também assegurou a convergência de interesses, o que reduziu a tensão e o enfrentamento nesse período.

Se esse período foi marcado por avanços importantes no campo da regulamentação sanitária, a disputa entre projetos políticos antagônicos, no campo da saúde, permaneceu afetando as decisões da Agência. Depreende-se que a publicidade das ações de vigilância sanitária tenha minimizado esse debate no âmbito do Conselho Nacional de Saúde. Além disso, o fato de a direção da Anvisa pertencer ao Partido dos Trabalhadores, que governou o país por boa parte do período estudado, também favoreceu, por meio de estratégias que criaram consensos em torno da legitimidade partidária. Se não se pode afirmar que houve cooptação, os resultados indicam que o diálogo estabelecido arrefeceu as críticas historicamente construídas sobre o modelo regulador da vigilância sanitária.

\section{A Comissão Intersetorial de Vigilância Sanitária e Farmacoepidemiologia}

A CIVSF foi instituída, juntamente com as outras seis comissões intersetoriais definidas no texto legal, por meio da Resolução CNS no 11, de 1991 (BRASIL, 1991). De acordo com essa normativa, as comissões intersetoriais são compostas por representantes de órgãos governamentais de âmbito nacional (e seus centros de referência) e de entidades civis relacionadas a suas temáticas, quer sejam de prestadores de serviços, de profissionais, de usuários ou de proteção e defesa do cidadão. 
Em 2007, a composição da CIVSF foi reestruturada e aprovada pela Resolução CNS no 385 (BRASIL, 2008): 11 membros titulares e os respectivos suplentes, mais um coordenador e um coordenador adjunto, que são conselheiros nacionais. A composição segundo entidades e segmentos, de acordo com a Resolução CNS no $385 / 2007$, está descrita no quadro 2 .

Quadro 2. Composição da Comissão Intersetorial de Vigilância Sanitária e Farmacoepidemiologia, segundo entidades, 2007

\begin{tabular}{|c|c|}
\hline TITULAR & SUPLENTE \\
\hline \multicolumn{2}{|c|}{ ENTIDADES DE PROFISSIONAIS DE SAÚDE } \\
\hline Central Única dos Trabalhadores - CUT & $\begin{array}{l}\text { Confederação Brasileira de Aposentados e } \\
\text { Pensionistas }\end{array}$ \\
\hline \multicolumn{2}{|c|}{ Sociedade Brasileira de Vigilância de Medicamentos - Sobravime } \\
\hline $\begin{array}{l}\text { Associação Brasileira de Pós-graduação em } \\
\text { Saúde Coletiva - Abrasco }\end{array}$ & Instituto de Defesa do Consumidor \\
\hline Conselho Federal de Medicina Veterinária & Associação Brasileira de Enfermagem \\
\hline $\begin{array}{l}\text { Entidades Médicas: Conselho Federal de } \\
\text { Medicina, Associação Médica Brasileira e } \\
\text { Federação Nacional dos Médicos }\end{array}$ & $\begin{array}{l}\text { Associação Nacional dos Servidores da } \\
\text { Vigilância Sanitária - Ansevs }\end{array}$ \\
\hline Federação Nacional dos Farmacêuticos & Conselho Federal de Farmácia \\
\hline \multicolumn{2}{|c|}{ ENTIDADES E MOVIMENTOS SOCIAIS DE USUÁRIOS DO SUS } \\
\hline \multicolumn{2}{|c|}{ Fórum Nacional de Entidades de Defesa dos Portadores de Patologia e Deficiência } \\
\hline \multicolumn{2}{|c|}{ ENTIDADES DE PRESTADORES DE SERVIÇOS DE SAÚDE } \\
\hline Confederação Nacional de Saúde & $\begin{array}{l}\text { Confederação das Santas Casas de } \\
\text { Misericórdia, Hospitais e Entidades } \\
\text { Filantrópicas }\end{array}$ \\
\hline \multicolumn{2}{|l|}{ REPRESENTANTES DO GOVERNO } \\
\hline \multicolumn{2}{|c|}{ Conselho Nacional de Secretários de Saúde - Conass } \\
\hline \multicolumn{2}{|c|}{ Conselho Nacional de Secretários Municipais de Saúde- Conasems } \\
\hline Agência Nacional de Vigilância Sanitária & Fundação Oswaldo Cruz \\
\hline
\end{tabular}

Fonte: própria autora. 
A composição da comissão não contempla a paridade entre usuários e demais membros, talvez por seu caráter mais de assessoramento técnico à plenária. Mais da metade das entidades que compõem a comissão correspondem às de profissionais de saúde. A participação das entidades nas 12 reuniões analisadas, no período de 2005 a 2010, está descrita no gráfico 1 .

\section{Gráfico 1. Percentual de participação nas reuniōes da Comissão Intersetorial de Vigilância Sanitária e Farmacoepidemiologia, segundo entidades, 2005 a 2010}

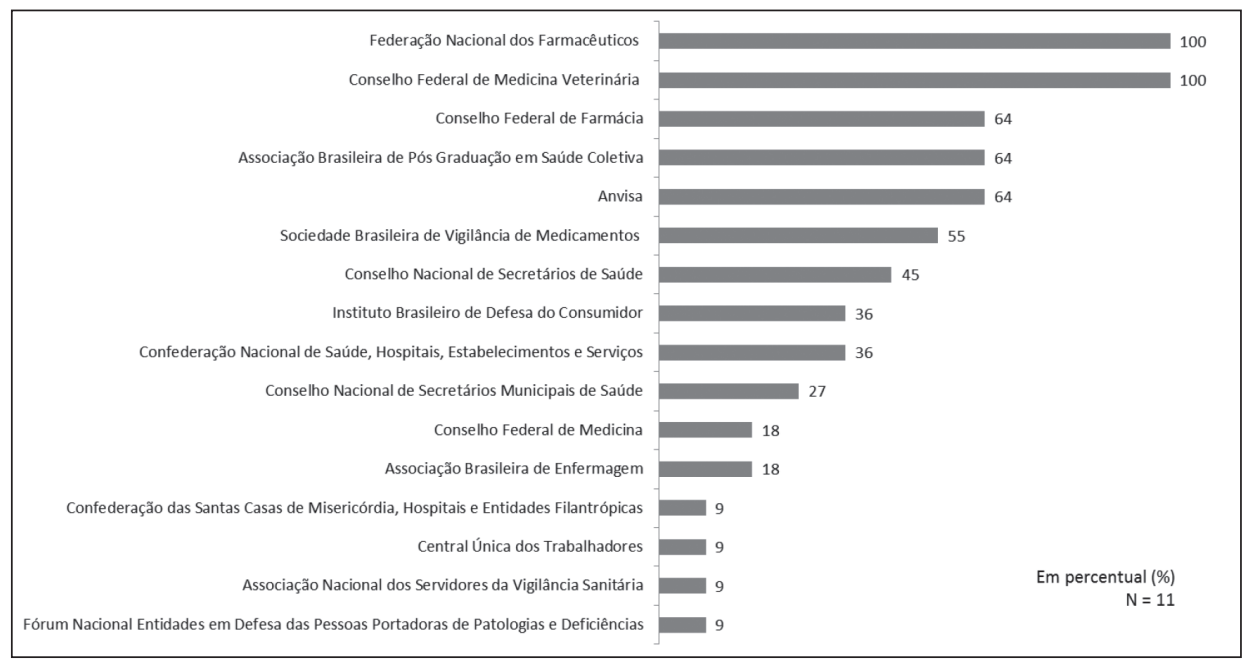

Fonte: própria autora.

No período de 2005 a 2010, a comissão realizou 18 reuniōes, das quais 11 estão registradas em atas. Nestas, dez entidades participaram de menos da metade das reuniōes, ou seja, de cinco reunióes ou menos. As entidades mais presentes foram a Federação Nacional dos Farmacêuticos (à qual pertencia o coordenador da comissão) e o Conselho Nacional de Medicina Veterinária. A Anvisa participou da maioria das reuniões, na condição de apresentação de pontos de pauta, porém em sete delas como membro da comissão. As atas acessíveis correspondem a duas reuniôes realizadas em 2005 e três em cada um dos seguintes anos: 2008, 2009 e 2010. Os temas debatidos durante as reuniōes estão condensados no quadro 3. 
Quadro 3. Temas debatidos nas reuniōes da Comissão Intersetorial de Vigilância Sanitária e Farmacoepidemiologia, 2005 a 2010

\begin{tabular}{|l|c|c|}
\hline \multirow{2}{*}{ TEMÁTICA } & \multicolumn{2}{c|}{ ITEM DE PAUTA } \\
\cline { 2 - 3 } & $\mathrm{N}$ & $\%$ \\
\hline Análise de políticas e programas de em vigilância sanitária & 12 & 32,5 \\
\hline Controle social em vigilância sanitária & 04 & 10,8 \\
\hline Bens e serviços sob regulação sanitária & 03 & 8,1 \\
\hline Organização e avaliação de eventos & 09 & 24,3 \\
\hline Planejamento e organização interna da Comissão & 09 & 24,3 \\
\hline TOTAL & 37 & 100 \\
\hline
\end{tabular}

Fonte: própria autora.

Apesar da relevância dos temas discutidos e da perspectiva crítica adotada pelos conselheiros durante as discussões, a comissão teve poucos encaminhamentos propositivos, a maior parte voltada para a discussão de novos temas em seu próprio âmbito. Após o debate, esses assuntos eram levados à Plenária do Conselho Nacional de Saúde por meio de informes, que correspondiam a relatos do coordenador da Comissão. Além disso, quase metade dos pontos discutidos se refere a assuntos de natureza operacional, como organização interna da comissão e sua participação em eventos.

Essa dinâmica não parece ter impactado positivamente sobre a baixa inserção da vigilância sanitária na agenda do Conselho Nacional de Saúde e a efetividade das decisões a ela relacionadas. Exemplo disso é o debate sobre a convocação da 2a Conferência Nacional de Vigilância Sanitária que, a despeito de ter sido aprovada como recomendação da $13^{a}$ Conferência Nacional de Saúde, nunca aconteceu.

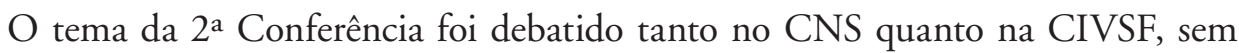
que isso resultasse em sua realização. Conclui-se que a comissão foi pouco efetiva em seu papel de se constituir um fórum para o debate sobre vigilância sanitária dentro do Conselho Nacional de Saúde. A baixa capacidade de encaminhamento de suas demandas, aliada à pouca assimilação, por parte do Conselho Nacional de Saúde, do tema, resultaram numa atuação pouco impactante e de baixa repercussão para as ações de vigilância sanitária. 


\section{Considerações finais}

A importância do debate sobre vigilância sanitária remete à importância do CNS na arena política da saúde, especialmente a partir da criação do SUS, quando assume o lugar de principal espaço de articulação nacional dos atores relacionados ao setor (CORTES, 2009). A análise das atas, moções e recomendações do Conselho Nacional de Saúde indica a forma de inserção da vigilância sanitária na agenda desse espaço de controle social do SUS. As questóes debatidas no Conselho Nacional de Saúde sobre vigilância sanitária, durante o período de estudo, apareceram de forma pontual, nos assuntos relacionados (especialmente política de assistência farmacêutica), ou como ponto de pauta, demandando debates específicos sobre o tema.

No primeiro período, preponderaram os debates relacionados à assistência farmacêutica e organização da I Conferência Nacional de Vigilância Sanitária, que aconteceu em 1999. Na segunda fase, de 2003 a 2005, embora com a perspectiva de fortalecimento do controle social na saúde, houve redução nos debates sobre vigilância sanitária. Com a reestruturação da Comissão Intersetorial de Vigilância Sanitária e Farmacoepidemiologia, os temas passaram a ser remetidos a essa instância. Além disso, nesse período a plenária do Conselho Nacional de Saúde decidiu pela não participação no Conselho Consultivo, por considerá-lo um espaço participativo frágil e precário. Na terceira fase, de 2006 a 2010, houve maior frequência de pontos de pauta sobre vigilância sanitária, o que o caracterizou como fase de maior aproximação entre o Conselho Nacional de Saúde e a Anvisa. Embora os debates incluíssem críticas quanto a sua atuação, foram emitidas oito moções de apoio a iniciativas e à gestão da Agência.

Se por um lado, há um reconhecimento da necessidade de maior aproximação do Conselho Nacional de Saúde em relação à vigilância sanitária, na prática o esforço mútuo não foi suficiente para concretizar essa relação. Após a reestruturação da CIVSF, em 2004, muitos dos assuntos sobre vigilância sanitária pautados no Conselho foram remetidos à comissão, para a apreciação e demais encaminhamentos. A comissão se tornou, a partir desse período, o espaço por excelência para a discussão da política de vigilância sanitária no CNS. O encaminhamento de várias questôes à Comissão Intersetorial de Farmacoepidemiologia e Vigilância Sanitária não contribuiu para essa 
aproximação, pois esta instância se mostrou pouco efetiva na disseminação de seus debates. O Conselho Nacional de Saúde voltou a fazer parte da composição do Conselho Consultivo apenas em 2010, o que não permite, neste estudo, avaliar se essa reinserção trará resultados efetivos para essa articulação.

A partir dessa análise, verifica-se a fragilidade de articulação e integração entre o Conselho Consultivo da Anvisa e as instâncias de controle social no SUS. A natureza do Conselho Consultivo, não deliberativa, e sua composição, majoritária do governo, sinalizam baixa capacidade de diálogo com a diversidade de forças da sociedade envolvidas nas questóes de saúde pública. O distanciamento e pequena capacidade de articulação ao Conselho Nacional de Saúde é expressão dessas dificuldades. No período, as recomendações do Conselho Consultivo não foram objeto de debate pelo Conselho Nacional de Saúde e, na mão inversa, o Conselho Consultivo também não assimilou as discussões daquele fórum sobre a vigilância sanitária.

Quanto a esse aspecto pesa, além das dificuldades de comunicação interinstitucional, a baixa inserção da vigilância sanitária no Sistema Único de Saúde, historicamente construída. Por seus métodos e instrumentos, a vigilância sanitária se configurou, ao longo do tempo, como prática burocrática, centrada no controle e normatização de bens e serviços em saúde. Mais recentemente, embora se apoiando em discursos técnicos/tecnocráticos e na (ainda tímida) produção de conhecimento, sua prática permanece calcada nos aspectos cartoriais-burocráticos. Ao mesmo tempo, permaneceu alheia (embora não neutra) aos debates e disputas que se formavam no campo da saúde entre os projetos privatizante da saúde e de defesa do SUS. Sem a realização de conferências temáticas nem adoção de estratégias para garantia das agendas propostas sobre o tema nos fóruns do SUS, a vigilância sanitária foi absorvida pela reforma gerencialista de Estado, com a adoção de um desenho institucional distinto, que a distanciou ainda mais das organizações integrantes do Sistema Único de Saúde.

\section{Referências}

ALVES, S. M. C. Processo de participação da sociedade civil nas consultas públicas realizadas pela Agência Nacional de Vigilância Sanitária - Anvisa: (2000-2006). 2008. 236 f. Dissertação (Mestrado em Política Social) -Faculdade de Ciências Humanas, Universidade de Brasília, Brasília, 2008. 
BRASIL. Resolução no 11, de 31 de outubro de 1991. Institui e normatiza o funcionamento das Comissões Intersetoriais de Alimentação e Nutrição, Saneamento e Meio Ambiente, Recursos Humanos para a Saúde, Ciência e Tecnologia em Saúde, Vigilância Sanitária e Farmacoepidemiologia, Saúde do Trabalhador, Saúde do Índio. Diário Oficial [da] República Federativa do Brasil, Brasília, DF, no 241, seção 1, p. 28717, dez. 1991.

BRASIL. Ministério da Saúde. Conselho Nacional de Saúde. Resolução no 385, de 14 de junho de 2007. Aprova a reestruturação da Comissão Intersetorial de Vigilância Sanitária e Farmacoepidemiologia - CIVSF. Diário Oficial [da] República Federativa do Brasil, Brasília, DF, no 21, seção 1, p. 114, jan. 2008.

BRASIL. Ministério da Saúde. Secretaria de Gestão Estratégica e Participativa. Conhecimento em Gestão Participativa: relatório e pesquisas. Brasília: Ministério da Saúde, 2007.

BRASIL. Presidência da República. Lei no 8.142, de 28 de dezembro de 1990. Dispõe sobre a participação da comunidade na gestão do Sistema Único de Saúde (SUS) e sobre as transferências intergovernamentais de recursos financeiros na área da saúde e dá outras providências. Diário Oficial [da] República Federativa do Brasil, Brasília, DF, no 249, Seção 1, p. 25694, dez. 1990.

BAIRD, M. F. O lobby na regulação da propaganda de alimentos da Agência Nacional de Vigilância Sanitária - Anvisa. 2012. 183p. Dissertação (Mestrado em Ciência Política). Faculdade de Filosofia, Letras e Ciências Humanas, Universidade de São Paulo, São Paulo, 2012.

BARDIN, L. Análise de conteúdo. Portugal: Edições 70, 1977.

BRAVO, M. I. S.; MENEZES, J. S. B. de. A Saúde no governo Lula e Dilma: algumas reflexões. In: (Org.). Cadernos de Saúde. Saúde na atualidade: por um sistema único de saúde estatal universal, gratuito e de qualidade. Rio de Janeiro: UERJ/Rede Sirius, 2011. p. 43-49.

CORREIA, M. V. C. Controle Social. In: Dicionário da educação profissional em saúde. PEREIRA, I. B.; LIMA, J. C. F. (Org.). Rio de Janeiro: EPSJV, 2008.

CORTES, S. M. V. Construindo a possibilidade da participação dos usuários: conselhos e conferências no Sistema Único de Saúde. Sociologias, n. 7, p. 18-49, 2002.

CORTES, S. M. V. Sistema Único de Saúde: espaços decisórios e a arena política de saúde. Cadernos de Saúde Pública, v. 25, n. 7, p. 1626-1633, 2009.

DAGNINO, E. Sociedade civil, espaços públicos e a construção democrática no Brasil: limites e possibilidades. In: Sociedade civil e espaços públicos no Brasil. São Paulo: Paz e Terra, 2002.

DASSO JUNIOR, A. E. Reforma do Estado com participação cidadã? 2006. 459p. Tese (Doutorado em Direito) - Centro de Ciências Jurídicas, Universidade Federal de Santa Catarina, Florianópolis, 2006. 
DINIZ, E. Globalização, reforma do Estado e teoria democrática contemporânea. São Paulo em Perspectiva, São Paulo, v. 15, n. 4, 2001.

ESCOREL, S.; BLOCH, R. A. As Conferências Nacionais de Saúde na construção do SUS. In: LIMA, N. T. et al. (org.). Saúde e democracia: história e perspectivas do SUS. Rio de Janeiro: Fiocruz, 2005. p. 83-120.

GUERREIRO, J. V.; BRANCO, M. A. F. Dos pactos políticos à política dos pactos na saúde. Ciência e Saúde Coletiva, v. 16, n. 3, p. 1689-1698, mar. 2011.

LABRA, M. E. Conselhos de Saúde: dilemas, avanços e desafios. In: LIMA, N. T. (Org.). Saúde e democracia: história e perspectivas do SUS. Rio de Janeiro: Fiocruz, 2005. p. 353-383. LUCENA, R. C. B. de. Os dilemas da participação institucionalizada: o caso do Conselho Consultivo da Agência Nacional de Vigilância Sanitária. 2013. 254p. Tese (Doutorado em Política Social) - Faculdade de Ciências Humanas, Universidade de Brasília, Brasília, 2013. MAIA, C. S.hristiane Santiago. Inserção da vigilância sanitária na política de saúde brasileira. 2012. 199p. Tese (Doutorado em Ciências da Saúde) - Faculdade de Ciências da Saúde, Universidade de Brasília, Brasília, 2012.

MARQUES, R. M.; MENDES, A. Servindo a dois senhores: as políticas sociais no governo Lula. Revista Katálisis, Florianópolis, v. 10, n. 1, p. 15-23, 2007.

VANDERLEI, M. I. G.; WITT, R. R. Conselhos de saúde: espaços de participação social, constituição de sujeitos políticos e co-produção de sujeitos coletivos. Saúde em Debate, v. 27, n. 64, p. 131-141, 2003.

\section{Notas}

${ }^{1}$ Segundo Cortes (2002), os diferentes conceitos empregados para definir participação e participantes estão vinculados a diferentes orientaçôes políticas e ideológicas que, por sua vez, adotam a perspectiva mercantil ou de direito social. A expressão "controle social" foi ganhando novos significados ao longo do tempo, tendo sido apropriada pela esquerda na conjuntura de redemocratização do Brasil para denominar as estratégias de participação da sociedade civil na formulação e acompanhamento das políticas públicas (CORREIA, 2008).

${ }^{2}$ Esta pesquisa não foi financiada, é resultado de tese de doutorado e não há conflitos de interesse envolvidos.

${ }^{3}$ Foram criadas as Secretarias: de Vigilância em Saúde, de Ciência e Tecnologia e Insumos Estratégicos, de Gestão do Trabalho em Saúde, de Gestão Participativa e de Atenção à Saúde; e extintas as Secretarias de Investimentos na Saúde, Políticas da Saúde e Assistência à Saúde. 


\section{Abstract}

The relationship between the Advisory Board of Anvisa and the National Health Council: an analysis from 2000 to 2010

The study examined the discussions, in the period from 2000 to 2010, in the National Health Council (CNS) and the Inter-Sectoral Commission for Health Surveillance and Pharmacoepidemiology (CIVSF) about issues related to health surveillance and the articulation with the Consultant Council of the National Health Surveillance Agency (Anvisa). The documentary research, of qualitative nature, that analyzed 163 records of meetings of the CNS and CIVSF, and other documents related, sought to gather information about the political-institutional context and interfaces and connections between the three spaces. There was low insertion of the topic of health surveillance in the CNS agenda and insufficient performance of CIVSF to strengthen this debate. We conclude there is weak integration between the Advisory Council of Anvisa and social control agencies in the SUS. This is the result of difficulties in interagency communication and low insertion of health surveillance in SUS, historically constructed.

> Key words: health surveillance; health policy; consumer participation. 